\title{
DIREITOS INTELECTUAIS SOBRE CONHECIMENTOS TRADICIONAIS
}

Salete Oro Boff

\section{RESUMO}

A dificuldade de dimensionar limites entre o conhecimento tradicional e 0 conhecimento científico dá margem a indagações sobre a apropriação de bens considerados (mesmo que em sentido simbólico) patrimônio da humanidade, como o genoma humano e das plantas, para transformá-los em produtos. Nesse contexto, o presente trabalho de investigação busca analisar a proteção legal dos conhecimentos tradicionais relacionados à biodiversidade e verificar se é possível vislumbrar uma posição de equilíbrio com o fim de reverter, de forma compartilhada, os benefícios da industrialização e da comercialização dos produtos que se baseiam nos conhecimentos tradicionais.

Palavras-chave: Biodiversidade. Conhecimentos tradicionais. Propriedade intelectual.

\section{CONHECIMENTOS TRADICIONAIS E BIODIVERSIDADE}

O conhecimento é uma construção contínua da humanidade. Apresentase, a partir de um processo evolutivo, sem que seja possível estabelecer o seu início. É certo, porém, que o conhecimento está imbricado ao espaço cultural e aos seus atores, resultado de uma diversidade de iniciativas criativas e inovadoras que se comungam ao longo dos tempos na forma de usos, de crendices, de invenções, de descobrimentos e aperfeiçoamentos de técnicas e de produtos. Portanto, resultado da comunhão do conhecimento empírico com o conhecimento científico (comprovados).

Assim, uma cultura é tão mais rica quanto mais saberes for possível integrar. "Os saberes comuns [...] resultam da experiência comum da vida em sociedade" e a "utilização proveitosa do conhecimento em forma de capital é tão antiga quanto o capitalismo industrial.", pois "a história da industrialização pode ser lida como a história do divórcio crescente entre o desenvolvimento dos conhecimentos científicos e técnicos, por um lado, e a cultura comum, por outro."

Pela denominação 'conhecimentos tradicionais' entendem-se as informações e as práticas de comunidades (indígenas ou outras que vivem em estreita relação com ambiente), que possam se transformar em valor, associadas ao patrimônio genético. É o conhecimento acerca das potencialidades curativas de determinada planta que é transmitido oralmente entre as gerações, que descobriram e identificaram seu uso. São apresentados pela OMPI como conhecimentos resultantes da prática diária, "criados a cada dia, e desenvolvidos como resposta de pessoas e comunidades aos desafios postos por seu meio social e físico"2. 
A utilização de conhecimentos tradicionais dos povos indígenas, seringueiros, agricultores, ribeirinhos e outros sobre recursos naturais como ponto de partida para direcionar as pesquisas é prática comum que leva ao estudo do potencial farmacológico (ou comestível) de determinada planta. Coletam-se os recursos biológicos e passa-se a estudá-los baseando-se no uso comum. Ao associar o conhecimento tradicional ao científico, dá-se um grande passo para o êxito das pesquisas e essa prática pode levar ao patenteamento de produtos e processos. ${ }^{3}$ Com esses procedimentos, desconsideram-se e desrespeitam-se os conhecimentos das culturas locais.

A apropriação do conhecimento, a biopirataria, resulta no registro dos produtos obtidos a partir das informações das comunidades locais, como propriedade privada, pelos 'caçadores de genes' que partem em expedições pelos países em busca de recursos genéticos valiosos, como as sementes de plantas comestíveis ou medicinais. As comunidades locais fornecem o material e, além disso, informações a respeito de suas qualidades alimentícias ou curativas. Os materiais são encaminhados a laboratórios especializados nos países desenvolvidos, onde são isolados e identificados os genes para posterior solicitação das patentes. ${ }^{4}$

Nesse contexto, acentua-se, nas últimas décadas, a preocupação com a diversidade biológica, em razão da crescente destruição do ambiente natural e da privatização do conhecimento. Resultado desse debate foi a Conferência sobre Diversidade Biológica (ECO92), que, já no seu artigo 1ํ.., destaca como objetivo a "conservação da diversidade biológica, a utilização durável de seus elementos e a justa e eqüitativa divisão dos recursos genéticos e uma transferência apropriada das técnicas pertinentes, levando em conta todos os direitos sobre esses recursos e técnicas e graças a um financiamento adequado" 5 .

Verifica-se, a partir da Convenção, a importância de manter e de conservar os conhecimentos e as práticas tradicionais das comunidades locais concomitante à utilização sustentável dos recursos genéticos, pois a "biodiversidade foi sempre um recurso local comunitário", que combina direitos e responsabilidade entre os usuários, "a cominação de utilização com preservação, um sentido de coprodução com a natureza e de dadiva entre os membros da comunidade" 6 .

\section{DIREITO DE PROPRIEDADE INTELECTUAL}

Essa imbricação entre conhecimento tradicional e científico utilizando materiais da biodiversidade eleva o papel do Direito como regulador e garantidor da convivência social, tendo em conta os interesses individuais, coletivos e difusos dos diferentes atores, resguardando os valores inerentes à dignidade da pessoa humana, à liberdade, à justiça e à paz.

Essas questões relacionam-se diretamente com 0 Direito de Propriedade, garantido pela Constituição Federal, o qual abarca o direito à propriedade privada, condicionado à sua função social. Imprime-se, nesse 
particular, uma função primordial ao Direito de Propriedade Intelectual, que compreende o conjunto de direitos que gozam os autores de obras intelectuais sobre as suas criações do espírito; fruto de "um esforço pessoal (trabalho) realizado pela inteligência e inspiração de uma pessoa (ou de um grupo de pessoas), com 0 apoio na sua experiência". ${ }^{7}$ A propriedade intelectual ${ }^{8}$ compreende dois ramos: o direito de autor e conexos e a propriedade industrial. $O$ direito de autor compreende as criações do imaginário humano, incluindo aproteção do software. No campo da propriedade industrial ${ }^{9}$, estão as patentes, as marcas, os desenhos e modelos industriais, as indicações geográficas e a concorrência desleal. É o produto da invenção e a expressão criativa, mais a proteção pública que se concede ${ }^{10}$.

Portanto, há que se registrar a importância que a propriedade intelectual vem adquirindo no contexto do desenvolvimento tecnológico e na medida do valor que agrega ao conhecimento tradicional. Como se sabe, a função da patente é "instrumentalizar, como propriedade dinâmica, o acesso e o controle do mercado, em benefício de empresas industriais que dispõem dos capitais suficientes para orientar o ritmo das pesquisas tecnológicas e de estrutura para controlar os mercados criados pelos produtos e procedimentos." 11 As patentes constituem "um privilégio temporário que o Estado concede a uma pessoa física ou jurídica pela criação industrial, suscetível de beneficiar a sociedade"12. Por essa definição, percebe-se que a patente pode ser entendida como um "acordo" entre 0 inventor e a sociedade/Estado.

Entendida como um contrato entre a sociedade e os inventores, a patente garante ao inventor o direito exclusivo de impedir, por um determinado período de tempo, que outras pessoas fabriquem, usem ou vendam a invenção patenteada, em troca da publicação (divulgação) dos detalhes da invenção. Se houver utilização por terceiros, caberá indenização ao inventor (pagamento de royalties), como forma de compensar os custos de tempo, dinheiro e esforço empreendidos para o desenvolvimento da invenção. ${ }^{13}$

Ocorre que, em muitas situações, a proteção pelo Direito de Propriedade Intelectual privilegia somente os direitos dos descobridores, mesmo que essas revelações se amparem nos conhecimentos tradicionais, impressos pelos povos com o passar dos tempos. Então, frente a essa configuração, é necessário repensar o tratamento legal costumeiramente empregado, visando a estabelecer o equilíbrio dos benefícios oriundos da exploração dos privilégios dos produtos resultantes do reconhecimento das descobertas.

Um fato que levou ao incremento do reconhecimento de produtos tradicionais foi a concessão, pelos Estados Unidos, de privilégios a organismos vivos per se, quando "obtidos em complicadas pesquisas genéticas"14. Apesar de ser questionada, essa concessão de patente pela Suprema Corte Norteamericana ${ }^{15}$ passou a enquadrar como invenção os "microorganismos per se como resultado final de um processo misto em que foram empregados seres vivos e objetos inanimados". ${ }^{16} \mathrm{Em}$ razão disso, "gigantes empresariais financiam expedições por todo o Hemisfério Sul, em busca de traços genéticos raros e originais que possam ter algum valor comercial." O grande interesse está no valor de que as "novas drogas derivadas de plantas, prescritas nos dias 
de hoje, eram utilizadas na medicina indígena. O curare, por exemplo, importante anestésico cirúrgico e relaxante muscular, é derivado de extratos vegetais utilizados pelos índios da Amazônia para paralisar a caça". ${ }^{17}$

Outro caso foi o do patenteamento de processos de utilização da neem, árvore nativa da Índia. ${ }^{18}$ Essa patente foi considerada como uma tentativa empresarial de patentear conhecimentos indígenas e recursos biológicos nativos. O isolamento do componente do neem, a azadiractina, por A W. R. Grace, recebeu várias patentes para os métodos e processos utilizados para a produção do extrato da neem. Mas os privilégios foram contestados pelos cientistas indianos, comprovando que os métodos e processos empregados já eram utilizados há séculos e que, em razão desse fato, as informações deveriam "ser livres e abertamente compartilhadas".

Essas situações repetem-se com freqüência, ainda mais com a globalização. Não bastasse isso, as empresas tentam reduzir a oposição às pesquisas impondo, pelo seu poderio econômico, "um sistema uniforme de propriedade intelectual, que vincule todos os países, conceda às multinacionais livre acesso ao material genético de todo o mundo e que, ao mesmo tempo, forneça proteção a seus produtos geneticamente construídos." ${ }^{19}$ É exemplo disso o TRIPs - Acordo sobre Aspectos dos Direitos de Propriedade Intelectual Relacionados ao Comércio -, na Rodada do Uruguai do Acordo Geral de Tarifas e Comércio (GATT).

As grandes empresas de biotecnologia estão copiando conhecimentos indígenas de milhares de anos e vasculham os centros de diversidade genética. Apropriam-se do conhecimento para, após, repassá-lo de volta, a altos preços, "sob uma forma levemente alterada e patenteada - os mesmos produtos que foram livremente partilhados e comercializados entre agricultores e camponeses por toda a história da humanidade."20

Além dos direitos de propriedade industrial, destacam-se, exemplificativamente, os direitos autorais dos índios, inseridos no texto constitucional, artigo 231, no qual se reconhece a organização social, os costumes, a língua, as crenças, as tradições indígenas e o caráter coletivo das mesmas e garante direitos sobre seus bens materiais e imateriais. A Constituição reconhece as manifestações culturais indígenas, que constituem o seu patrimônio cultural. A legislação infra-constitcional federal e estadual ocupa-se da temática, como o Estatuto do Índio, Lei n‥ 6.001/73, assegurando genericamente o respeito ao patrimônio cultural das comunidades indígenas e criminalizando algumas ações que violem a sua imagem, ou de seus membros, e expressões de sua cultura. ${ }^{21}$

Mas, mesmo amparados pela legislação, os bens imateriais que constituem a expressão de suas culturas (cantos, desenhos, pinturas e mitos) "não raro têm sido utilizados de maneira indevida, sem que lhes seja facultado o acesso a instrumentos eficazes de proteção dos seus direitos. $O$ assédio e as investidas quanto ao uso da imagem e dos bens culturais indígenas crescem em quantidade e complexidade, estabelecendo para os índios e suas organizações um novo campo de questões. "22 
Certamente que essas culturas merecem compartilhar os resultados obtidos na comercialização dos produtos, ao mesmo tempo em que se tornaria obrigatório 0 "[...] consentimento prévio das comunidades para o acesso aos recursos situados em suas terras. [...] o atual sistema patentário reconhece e protege apenas os conhecimentos produzidos individualmente, o que não corresponde ao caso das comunidades, em que o conhecimento é produzido coletivamente."

Assim, parece indiscutível reconhecer os direitos de propriedade intelectual e por outro lado, compensar os esforços empreendidos há anos pelos membros das comunidades, pois as informações tradicionais associadas contribuem para o incremento de novas descobertas. Esse fato leva à necessidade de criação de um regime legal diferenciado que passe a reconhecer os conhecimentos tradicionais associados às pesquisas e que atente para a divisão dos benefícios provenientes da industrialização e comercialização, além de obter o consentimento prévio das comunidades locais para o acesso dos produtos localizados nos seus domínios.

Existem posições mais radicais, como de algumas ONGs - Organizações não Governamentais -, que defendem que o domínio genético não pode ser vendido a qualquer preço e deve continuar a ser domínio de todos, usado livremente pelas gerações presentes e futuras, transformando esses locais de domínio de preservação global, porém livre da exploração comercial. ${ }^{23}$

\section{DIREITOS INTELECTUAIS SOBRE CONHECIMENTOS TRADICIONAIS}

$\mathrm{Na}$ esfera internacional, o TRIPs - Acordo sobre Aspectos dos Direitos de Propriedade Intelectual Relacionados ao Comércio -, específico para a área de propriedade intelectual, nada contemplou sobre os conhecimentos tradicionais, deixando a cargo dos países membros a proteção ou não de plantas e animais e dos processos para sua obtenção. Recentemente foi apresentada proposta de emenda nesse sentido, na Conferência da Organização Mundial do Comércio, em Doha (2001).

A Convenção sobre Diversidade Biológica ${ }^{24}$ refere à expressão consentimento prévio fundamentado: "O acesso aos recursos genéticos deve estar sujeito ao consentimento prévio fundamentado da Parte Contratante provedora desses recursos, a menos que de outra forma determinado por essa Parte". Reconhece em seu preâmbulo a dependência de recursos biológicos de muitas comunidades locais e populações indígenas com estilos de vida tradicionais, e imprime o dever de preservação do conhecimento e das práticas das comunidades locais e indicar a repartição dos benefícios oriundos da aplicação destes conhecimentos.

O instituto das patentes, como já observado, não protege 0 conhecimento tradicional associado aos recursos genéticos e nem admite a patente sobre plantas, Lei de Propriedade Industrial, n. 9.279/96. Na mesma esteira não se revela possível proteger os conhecimentos tradicionais por meio 
dos Direito de Autor, Lei n. 9.610/98, que tem como requisito a originalidade da obra.

Concomitante, a Lei de Cultivares, n. 9.456/97, protege as variedades de vegetais, refere-se à planta como um todo, considera o conjunto de suas características. Para a concessão dessa distinção, é necessário que haja os requisitos da 'novidade, originalidade, e utilidade do bem'. A proteção dos cultivares não segue a rigidez dos requisitos à atribuição de patente de invenção. Para conseguir o registro do vegetal, são necessárias as características da distintividade, da homogeneidade e da estabilidade. Porém, embora o detalhamento da matéria, não há referência à proteção dos conhecimentos tradicionais.

Elabora-se uma Medida Provisória, n. 2.186-16, de 23 de agosto de 2001, como início da regulamentação em nível interno dos conhecimentos tradicionais, relacionando-os ao patrimônio genético existente na plataforma continental e na zona econômica exclusiva. A MP prevê o pagamento de royalties apenas para a transferência de tecnologias sujeitas a patente.

Soma-se a essa tentativa de regulamentação o Projeto de Lei n. 306/95, que inclui a proteção dos recursos biológicos e genéticos continentais, costeiros, marítimos e insulares presentes no território nacional. O Projeto prevê a participação da comunidade local nas decisões e nos benefícios não só econômicos, mas também sociais decorrentes do acesso aos recursos genéticos, inclusive assegura às comunidades o direito de não permitir a coleta de recursos naturais e o acesso ao conhecimento tradicional.

Recentemente, renova-se a preocupação com a utilização dos recursos biológicos, sem que a permissão ou o conhecimento das comunidades detentoras naturais dos direitos de exploração desses recursos. Para respaldar esse propósito, o Conselho de Gestão do Patrimônio Genético (CGEN), vinculado ao Ministério do Meio Ambiente, e o Instituto Nacional de Propriedade Intelectual (INPI), expediram as Resoluções 23 e 134, respectivamente, vinculando a concessão de patentes de invenção de produtos derivados da biodiversidade ao cumprimento das previsões da MP 2.186-16/01, informando os dados da autorização de acesso ao material e/ou informação, a origem do material genético ou do conhecimento tradicional associado e a repartição dos benefícios. ${ }^{25}$

Apesar da abrangência interna desses 'esforços' legislativos visando resguardar interesses nacionais, os mesmos poderão servir em nível internacional, como parâmetros para as negociações que tenham como mote o combate ao uso inadequado de recursos da biodiversidade de um país em outro. 


\section{EM BUSCA DE UM 'NOVO' ESPAÇO PARA A PROTEÇÃO DO CONHECIMENTO TRADICIONAL}

A repartição dos benefícios gerados a partir da utilização dos conhecimentos tradicionais apresenta-se como tentativa de promover a "justiça social global", uma vez que geralmente "a diversidade biológica no mundo está distribuída de forma inversamente proporcional ao acúmulo de capital financeiro e tecnológico". Os países, embora detentores de "grande parte da biodiversidade do planeta, sem contar com apoio financeiro e desenvolvimento tecnológico capaz de dirigir o uso da biodiversidade a patamares de sustentabilidade". ${ }^{26}$

A temática tem merecido atenção em nível internacional. A OMPI Organização Mundial de Propriedade Intelectual - busca encontrar formas de proteção do conhecimento tradicional, como a iniciativa recente de criação de um Fundo Voluntário para as Comunidades Indígenas e Locais ${ }^{27}$. Ainda, 0 Comitê Intergovernamental sobre Propriedade Intelectual e Recursos Genéticos, Conhecimentos Tradicionais e Folclore, órgão da OMPI, tem examinado as opções jurídicas de proteção das expressões culturais tradicionais, nas esferas jurídicas regionais e nacionais vigentes e as formas de proteção que pode recorrer na área da propriedade intelectual, considerando as legislações vigentes nos países. As impressões do Comitê traçam o caminho para as decisões futuras dos Estados-Membros da OMPI sobre o contexto da proteção que os conhecimentos tradicionais possam ter.

Durante a nona sessão o Comitê Intergovernamental apresentou um documento visando orientar e subsidiar a proteção dos conhecimentos tradicionais. O trabalho do Comitê projeta o reconhecimento do valor dos conhecimentos e expressões a culturais tradicionais, admitindo que a cultura constitua marco de inovação e criatividade que, em suma, beneficiam toda a humanidade; promove o respeito pelos povos locais, procurando contribuir para o bem estar desses povos, incluindo medidas políticas e jurídicas, com vistas a impedir a apropriação indevida de suas expressões culturais e seus derivados, controlando a forma de utilização fora do contexto tradicional e promovendo a participação eqüitativa dos benefícios de sua utilização. Acrescente-se a salvaguarda das culturas tradicionais, a promoção da inovação e da criatividade nas comunidades, recompensando-as e protegendo-as, levando a contribuir para a diversidade cultural, a promover o desenvolvimento das comunidades e a impedir a concessão de privilégios pelos direitos intelectuais não autorizados. ${ }^{28}$

\section{CONSIDERAÇÕES FINAIS}

A proteção da propriedade intelectual impulsiona o desenvolvimento econômico e de novas pesquisas. Entretanto, as legislações nacionais e internacionais na área da propriedade intelectual se mostram insuficientes para assegurar a proteção dos conhecimentos tradicionais. Percebe-se, entretanto, uma preocupação crescente no sentido de promover a participação das comunidades nos resultados do desenvolvimento de produtos a partir dos 
conhecimentos, como na utilização de material da biodiversidade, que podem ser úteis no desenvolvimento de novas drogas medicinais.

Nessa seara, parece prudente encaminhar a criação de novas categorias reivindicatórias e gestoras dos direitos, como as que ampliam a idéia de que as comunidades locais possam potencializar e articular tecnologias, considerando a propriedade coletiva de seus conhecimentos e compartilhando os resultados. Essa medida configura-se como alternativa à hegemonia dos grandes grupos comerciais por um lado e, por outro, pode representar a sobrevivência e a mantença do patrimônio natural e cultural das comunidades locais.

\begin{abstract}
The difficulty of dimensional limits between the traditional knowledge and the scientific knowledge gives to edge the investigations on the appropriation of considered goods (exactly that in symbolic direction) patrimony of the humanity, as the human genome and of plants, to transform them into products. In this context, the present work of inquiry searchs to analyze the legal protection of the traditional knowledge related to biodiversity and to verify if it is possible to glimpse a position of balance with the end to revert, of shared form, the benefits of the industrialization and the commercialization of the products that if base on the traditional knowledge.
\end{abstract}

Keywords: Biodiversity. Copyright. Traditional knowledge.

\title{
NOTAS
}

Pós-Doutoranda em Direito - UFSC - Área Propriedade Intelectual. Doutora em Direito UNISINOS. Pesquisadora. Advogada. Professora da IMED - Faculdade Meridional.

1 GORZ, André. O Imaterial. Conhecimento, valor e capital. Trad. Celso Azzan Júnior. São Paulo, 2005, p. 10; 32-33.

2 ADIERS, Cláudia Marins. A propriedade intelectual e a proteção da biodiversidade dos conhecimentos tradicionais. In. Revista da ABPI, nr. 56, jan.fev 2002. p. 59.

3 BARBOSA, Denis Borges. Uma introdução à propriedade intelectual. Rio de Janeiro: Lúmen Júris, 1998, p. 69.

4 Vejam-se alguns exemplos de espécies brasileiras patenteadas no exterior: $\mathrm{O}$ caso mais famoso, porém, é o do professor da Faculdade de Medicina de Ribeirão Preto, Sérgio Ferreira, que descobriu no veneno da jararaca uma substância capaz de controlar a pressão arterial. Sem dinheiro para tocar as pesquisas, ele aceitou uma parceria com o laboratório americano Bristol-Myers Squibb e, em troca dos recursos, a empresa registrou a patente do princípio ativo Captopril, uma marca que gera US\$ 2,5 milhões ao ano em royalties, e o Brasil também tem de pagar.

$[\ldots]$

Bubiri - Suas sementes são usadas há séculos pelos índios wapixana, de Roraima, como anticoncepcional. O laboratório canadense Bolink patenteou o princípio ativo e já desenvolve pesquisa com a substância para tratar a AIDS.

$[\ldots]$

Curare - Mistura de ervas guardada em sigilo pelos índios e usada na ponta das flechas como veneno para imobilizar a presa. Foi patenteado pelos EUA na década de 40 e é usado na produção de relaxantes e anestésico cirúrgico. 
Espinheira-santa - Seu extrato é um excelente remédio contra a gastrite. A empresa japonesa Nippon Mek Japan patenteou sua propriedade.

Jaborandi - Já transformado em remédio - Salegen - pelo laboratório alemão Merk, a planta é o antídoto contra a xerostoma (dificuldade salivar). Pesquisas do mesmo laboratório baseadas na cultura indígena e dos caboclos devem produzir para muito breve um remédio contra a calvície. O jaborandi também é bom para combater infecções pulmonares.

$[\ldots]$

Quebra-pedra - Usada pelos índios para tratar problemas hepáticos e renais, foi patenteada por uma empresa americana para a fabricação de medicamento para hepatite B.

5 Convenção sobre Diversidade Biológica, artigo $1^{\circ}$.

6 ADIERS, op. cit., 2002, p. 56; SHIVA, Vendana. Biopirataria - a pilhagem da natureza e do conhecimento. Trad. Laura Cordellini Barbosa de Oliveira. Rio de Janeiro: Vozes, 2001, p. 92-93.

7 FERREIRA FILHO, Manoel Gonçalves. A propriedade intelectual e o desenvolvimento tecnológico sob o prisma da Constituição brasileira. In. Anais do XXII Seminário Nacional da Propriedade Intelectual, 2002, p. 27.

8 A Organização Mundial de Propriedade Intelectual - OMPI define a propriedade intelectual como a "[...] soma dos direitos relativos às obras literárias, artísticas e científicas, às interpretações dos artistas intérpretes e às execuções dos artistas executantes, aos fonogramas e às emissões de radiodifusão, às invenções em todos os domínios da atividade humana, às descobertas científicas, aos desenhos e modelos industriais, às marcas industriais, comerciais e de serviço, bem como às firmas comerciais e denominações comerciais, à proteção contra a concorrência desleal e todos os outros direitos inerentes à atividade intelectual nos domínios industrial, científico, literário e artístico."

$9 \quad$ A Lei 9.279, de 14.05.1996, disciplina essas matérias.

10 SHERWOOD, Robert M. Propriedade intelectual e desenvolvimento econômico. Trad. Heloísa de Arruda Villela. São Paulo: EDUSP, 1992, p. 22.

11 PIMENTEL, Luiz Otávio. Las funciones del derecho mundial de patentes. Argentina: Advocatus, 2000, p. 225.

12 FURTADO, Lucas Rocha. Sistema de propriedade industrial no direito brasileiro. Brasília: Brasília Jurídica, 1996, p. 43.

13 CHINEN, Akira. Know-how e propriedade industrial. Belo Horizonte: Del Rey, 1997, p. 6.

14 DOMINGUES, 1989-b, op. cit., p. 5.

Nesse sentido, as observações de Salvador Dario Bergel: "En 1985 la Sala de Apelaciones de la Oficina de Patentes de los Estados Unidos decidió el caso Hibberd, admitiendo la patenteabilidad de plantas, semillas y cultivos de tejidos vegetales. De esta forma, se estableció que las leyes de protección de variedades vegetales y de patentes no se excluyen pudiéndose proteger las plantas de reproducción vegetativa por vía de patentes no se excluyen pudiéndose proteger las plantas de reproducción vegetativa por vía de patentes de plantas y patentes de utilidad (patentes propiamente dichas en la terminología norte-americana).

15 A concessão de patente deu-se por decisão da Suprema Corte Norte-americana no caso Diamond V. Chakrabarty. Segundo Douglas Gabriel Domingues, "(...) em 1972, Ananda Chakrabarty, microbiologista da Universidade de Illinois, utilizando técnicas de engenharia genética, obteve uma variedade microbiológica capaz de degradar componentes de óleo cru. Concebeu, também, recipiente para armazenar os microrganismos e processo para transporte dos mesmos". In. DOMINGUES, 1989-b, op. cit., p. 18-19.

16 Conforme Douglas Gabriel Domingues, houve uma decisão anterior da Corte germânica envolvendo o assunto, contudo esta se referia ao BGH, reportando-se "às funções biológicas do microorganismo per se como processo ou meio idôneo de produzir um resultado final de um processo misto em que foram empregados seres vivos e objetos inanimados. In. DOMINGUES, 1989-a, op. cit., p. 7.

17 RIFKIN, Jeremy. O Século da biotecnologia. Trad. Arão Sapiro. São Paulo: MAKRON Books, 1999, p. 52.

18 Idem, ibidem, p. 52-53 
19 Idem, ibidem, p. 54. Cita o autor: "Entre as empresas, estão muitas das grandes participantes no campo da biotecnologia, como Bristol Myers, Merck, Pfizer, Monsanti e Du Pont."

20 Idem, ibidem, p. 54.

21 Disponível em: http://www.socioambiental.org/, acesso em: 03.01.08.

22 Disponível em: http://www.socioambiental.org/, acesso: em 03.01.08.

23 RIFKIN, 1999, op. cit. p. 57.

24 No item 5 do art. 15 da Convenção de Biodiversidade.

25 As Resoluções do CGEN e do INPI passaram a ter vigências a partir de 02 de janeiro de 2007. Resolução CGEN de 10 de novembro de 2006. A Resolução n. 134/06 normatiza os procedimentos relativos ao requerimento de pedidos de patentes cujo objeto tenha sido obtido em decorrência de um acesso a amostra de componente do patrimônio genético nacional. "O Brasil elegeu o certificado de procedência legal ( que inclui a declaração de origem) como mecanismo de rastreamento para repartição de benefícios." In: NOVION, Henry Philippe Ibañez de; BAPTISTA, Fernando Mathias. O certificado de procedência legal no Brasil: estado da arte da implementação da legislação. Documentos de investigación. Instituto Socioambiental. Ano 2, n. 5, marzo, 2006. p. 2.

26 NOVION, Henry Philippe Ibañez de; BAPTISTA, Fernando Mathias. O certificado de procedência legal no Brasil: estado da arte da implementação da legislação. Documentos de investigación. Instituto Socioambiental. Ano 2, n. 5, marzo, 2006. p. 1.

27 Anexo ao documento WO/GA/32/6, aprovado pela Assembléia da OMPI (32ª ${ }^{-}$Seção).

28 Conforme WIPO/GRTKF/IC/9/4, anexo, p. 3.

\section{REFERÊNCIAS}

ADIERS, Cláudia Marins. A propriedade intelectual e a proteção da biodiversidade dos conhecimentos tradicionais. In. Revista da ABPI, nr. 56, jan.fev 2002. p. 48-65.

AMILS, Ricardo. Impacto de la biotecnologia em el médio ambiente. In. PALACIOS, Marcelo. Bioética. Llanera (Astúrias): Nobel, 2000. p. 387-403 .

AREND, Hannah. A condição humana. 10. ed. Rio de Janeiro: Forense Universitária, 2000.

BARBOSA, Denis Borges. Uma introdução à propriedade intelectual. Rio de Janeiro: Lúmen Júris, 1998.

BARRAL, Welber (org.). Direito e Desenvolvimento: análise da ordem jurídica brasileira sob a ótica do desenvolvimento. São Paulo: Editora Singular, 2005.

BECK, Ulrich.; GIDDENS, Anthony; LASH, Scott. Modernização reflexiva: política, tradição e estética na ordem social moderna. São Paulo: UNESP, 1997.

BERGEL, Salvador Darío. Requisitos y excepciones a la patentabilidad. Invenções biotecnológicas. In: CORREA, Carlos M. (Coord). Derecho de patentes. El nuevo régimen legal de las invenciones y los modelos de utilidad. Buenos Aires: Fundación Centro de Estudios Políticos Y Administrativos. 1996, 13-81.

Biopirataria, Disponível em: www.biopirataria.org, acesso em: 25/02/07.

BOFF, Salete Oro. Acordos e Tratados internacionais em matéria de patentes na biotecnologia e Legislação brasileira. In: DEL OLMO, Florisbal de Souza; ARAÚJO, Luís Ivani de Amorim (coord.) O Direito de família contemporâneo e os novos direitos. Rio de Janeiro: Forense, 2006, p. 303-324. 
. Os direitos humanos como paradigma regulador do patenteamento de genes. In: FERREIRA JÚNIOR, Lier Pires; MACEDO, Paulo Emílio Vauthier Borges (Coord.). Direitos humanos e direito internacional. Curitiba: Juruá, 2006, p. 357-366.

. Patentes na biotecnologia - Invenção versus descoberta. In: ADOLFO, Luiz Gonzaga da Silva; WACHOWICZ, Marcos (coord.). Direito da propriedade intelectual - Estudos em homenagem ao Pe. Bruno Jorge Hammes, 2006, p. 261-280.

BOFF, Salete Oro e CERVI, Taciana Marconatto Damo. Biotecnologia versus questões ambientais: pontos controvertidos na liberação de OGMs. Revista Direito e Justiça - reflexões sócio-jurídicas. Santo Ângelo: EDIURI, set/2004. p. 101-120.

CAPELLA, Juan Ramón. Fruto Proibido. Uma aproximação histórico-teórica ao estudo do Direito e do Estado. Porto Alegre: Livraria do Advogado, 2002.

CAPRA, Fritjof. As conexões ocultas. Ciência para uma vida sustentável. Trad. Marcelo Brandão Cipolla. São Paulo: Cultrix, 2002.

CHINEN, Akira. Know-how e propriedade industrial. Belo Horizonte: Del Rey, 1997.

CUNHA, Manuela Carneiro. Biodiversidade, justiça e ética. Revista do CEJ. nr. 8. mai/ago 99, Brasília: Conselho da Justiça Federal.

DEL NERO, Patrícia Aurélia. Propriedade intelectual. A tutela jurídica da biotecnologia. São Paulo: RT, 1998.

DEL'OLMO, Florisbal de Souza. Direito internacional privado. 6. ed. Rio de Janeiro: Forense, 2006.

DEMO, Pedro. Participação é conquista. 5. ed. São Paulo: Cortez, 2001.

. Introdução à sociologia. São Paulo: Atlas, 2002.

. Conhecimento moderno. Sobre ética e intervenção do conhecimento.

Petrópolis-RJ: Vozes, 1997.

DOMINGUES, Douglas Gabriel. Privilégios de invenção, engenharia genética e biotecnologia. Rio de Janeiro: Forense, 1989-a.

- Primeiras patentes de invenção de animal superior e a proteção legal dos embriões. Rio de Janeiro: Forense, 1989-b.

DUPAS, Gilberto. O mito do progresso. São Paulo: UNESP, 2006.

FROTA, Maria Stela Pompeu Brasil. Proteção de patentes e produtos farmacêuticos. O caso brasileiro. Brasília: FUNAG/IPRI, 1993.

FUKUYAMA, Francis. Nosso futuro pós-humano. Conseqüências da revolução da biotecnologia. Rio de Janeiro: Rocco, 2003.

FURTADO, Lucas Rocha. Sistema de propriedade industrial no direito brasileiro. Brasília: Brasília Jurídica, 1996.

GAMA CERQUEIRA, João da. Tratado de propriedade industrial. Rio de Janeiro: Forense, v. II, t. I, Parte II, 1952.

GIDDENS, Anthony. A terceira via. Rio de Janeiro: Record, 2005. 
GORZ, André. O Imaterial. Conhecimento, valor e capital. Trad. Celso Azzan Júnior. São Paulo, 2005.

HABERMAS, Jürgen. Teoria da ação comunicativa. vol. 1. Frankfurt a. Maio: Suhrkamp, 1981.

. Ciencia y técnica como "ideologia". Trad. Manuel Jiménez Redondo y Manuel Garrido. Madrid: Tecnos, 1999.

HAMMES, Bruno Jorge. O direito da propriedade intelectual. Subsídios para o ensino. 3. ed. São Leopoldo: UNISINOS, 2002.

Reflexões sobre a privilegiabilidade dos inventos de medicamentos e de gêneros alimentícios. Revista Estudos Jurídicos. São Leopoldo: UNISINOS, n. 53, 1988, p. 49-76.

HOSSNE, William Saad. Poder e injustiça na pesquisa com seres humanos. In. MACEDO, Maria Fernanda Gonçalves e BARBOSA, A L. Figueira. Patentes, Pesquisa \& Desenvolvimento: um manual de propriedade intelectual. Rio de Janeiro: FIOCRUZ, 2000.

MATTOS, Cláudio O. Justaposições como invento científico. Revista Biotecnologia, Ciência \& Desenvolvimento. Brasília, Ano I, número 5, março/abril, 1998, p. 26-27.

MORENO, P. C. Breuner. Tratado de patentes de invencion. Buenos Aires: Abeledo-Perrot, 1957, v. I.

MORIN, Edgar. Ciência com consciência. Rio de Janeiro: Bertrand Brasil, 1996.

NOVION, Henry Philippe Ibañez de; BAPTISTA, Fernando Mathias. O certificado de procedência legal no Brasil: estado da arte da implementação da legislação. Documentos de investigación. Instituto Socioambiental. Ano 2, n. 5, marzo, 2006. p. 1.

OLIVEIRA, Ubirajara Mach de. A proteção jurídica das invenções de medicamentos e de gêneros alimentícios. Porto Alegre: Síntese, 2000.

PAREJA, Enrique Láñez. Patentes biotecnológicas. Disponível em: www.ugr.es/, acesso em: 24.06.2002.

PIMENTEL, Luiz Otávio. Las funciones del derecho mundial de patentes. Argentina: Advocatus, 2000.

Síntese, 1999.

Direito industrial. As funções do direito de patentes. Porto Alegre:

PLASSERAUD, Yves e SAVIGNON, Françóis. L'etat et l'invention-historie des brevets. Paris: Documentation française, Institut National de la Propriete Industrielle, 1986.

RAYOL, Alice. Tendências de exame dos pedidos de patente na área da biotecnologia. Revista da ABPI, nr. 63. mar/abr 2003, p. 49-56.

RIFKIN, Jeremy. O Século da biotecnologia. Trad. Arão Sapiro. São Paulo: MAKRON Books, 1999.

SANTILLI, Juliana. Socioambientalismo e novos direitos. São Paulo: Petrópolis, 2005. 
SHERWOOD, Robert M. Propriedade intelectual e desenvolvimento econômico. Trad. Heloísa de Arruda Villela. São Paulo: EDUSP, 1992.

SHIVA, Vendana. Biopirataria - a pilhagem da natureza e do conhecimento. Trad. Laura Cordellini Barbosa de Oliveira.Rio de Janeiro: Vozes, 2001, p. 9293.

SILVEIRA, Newton. Curso de propriedade industrial. 2. ed. São Paulo: RT, 1987.

TECPAR. Disponível em: www.tecpar.br/appi

SOCIOAMBIENTALISMO. Disponível em: http://www.socioambiental.org/, acesso: em 03.01.08.

Recebido para publicação 06/11/2008

Aceito para publicação 19/12/2008 